\title{
A Guarda Compartilhada na Prática: Estudo de Casos Múltiplos
}

\author{
Lila Maria Gadoni-Costa ${ }^{1}$ \\ Giana Bitencourt Frizzo \\ Rita de Cássia Sobreira Lopes \\ Programa de Pós-Graduação em Psicologia da Universidade Federal do Rio Grande do Sul, \\ Porto Alegre, RS, Brasil
}

\section{Resumo}

Este estudo teve como objetivo investigar a guarda compartilhada na prática. Realizou-se um estudo de casos múltiplos com quatro famílias que optaram pela modalidade de guarda compartilhada após a separação conjugal. Os dados foram obtidos a partir de entrevistas semiestruturadas, realizadas individualmente com cada pai e mãe. Após, os dados foram submetidos à análise qualitativa, através da técnica de síntese de casos cruzados. A partir das categorias guarda compartilhada e coparentalidade, constatou-se que a aplicação da guarda compartilhada foi considerada positiva tanto pelos pais, como pelas mães entrevistados, embora também tenham sido constatadas dificuldades. Os genitores relataram a manutenção do envolvimento e participação na vida dos filhos após a separação, o que foi facilitado pelo compartilhamento da guarda. Entre as principais dificuldades relatadas foram mencionados: novo casamento de um dos genitores, manejo na rotina e horários dos filhos, entre outros. A coparentalidade entre as díades parentais se revelou positiva na maior parte do tempo, o que certamente contribuiu para que os novos arranjos fossem bem sucedidos e as dificuldades superadas. A cooperação entre os genitores também apareceu como importante no ajustamento dos filhos após a separação.

Palavras-chave: Guarda compartilhada, coparentalidade, família.

\section{The Joint Custody in Practice: Multiple Case Study}

\begin{abstract}
This study aimed to investigate the practice of joint custody. A multiple case study was conducted with four families who have chosen joint custody after divorce. Data were obtained from semi-structured interviews held individually with each parent and were subjected to qualitative analysis by synthesis of crossed cases technique. From joint custody and co-parenting, it was found that the application of joint custody was considered positive by both parents, although difficulties have also been observed. Parents reported the maintenance of involvement and participation in their children's lives after separation, which was facilitated by joint custody. Among the main difficulties reported were: new marriage of a parent, children's routine and schedule management, etc. Coparenting among parental dyads was found
\end{abstract}

Endereço para correspondência: Universidade Federal do Rio Grande do Sul, Instituto de Psicologia, Rua Ramiro Barcelos, 2600, sala 124, Bairro Santa Cecília, Porto Alegre, RS, Brasil 90035-003. E-mail: lilamariacosta@gmail.com, gifrizzo@gmail.com e sobreiralopes@portoweb.com.br

Esse estudo é derivado da tese de doutorado da primeira autora, sob co-orientação da segunda autora e orientação da terceira autora. 
to be positive most of the time, which certainly contributed to new arrangements success and overcome difficulties. The cooperation between parents was also important in the adjustment of children after separation.

Keywords: Joint custody, coparenting, family.

\section{La Custodia Compartida em la Práctica: Estudio de Casos Múltiplos}

\section{Resumen}

Este estudio tuvo como objetivo investigar la custodia compartida en la práctica. Se realizó un estudio de casos múltiples con cuatro familias que han optado por la modalidad de la custodia compartida después del divorcio. Los datos se obtuvieron a partir de entrevistas semiestructuradas realizadas individualmente con cada padre y cada madre. Después los datos fueron sometidos a un análisis cualitativo mediante la técnica de los casos cruzados. Desde clases de custodia compartida y coparentalidad de los hijos, se encontró que la aplicación de la custodia compartida se consideró positiva por ambos padres, como las madres entrevistadas, aunque también se han observado dificultades. Los padres y madres informaron el mantenimiento de la implicación y la participación en la vida de sus hijos después de la separación, que fue facilitado por compartir la guardia. Entre las principales dificultades señaladas se mencionaron nuevo matrimonio de uno de sus padres, en el manejo rutinario de los horarios y los niños, entre otros. La coparentalidad entre díadas parentales resultó positiva la mayor parte del tiempo, lo que sin duda contribuyó a que los nuevos arreglos tuvieron éxito y superar las dificultades. La cooperación entre los padres también apareció como importante en la adaptación de los niños después de la separación.

Palabras clave: Custodia compartida, coparentalidad, familia.

O número de separações/divórcios tem aumentado consideravelmente ao longo dos últimos anos em diversos países, constituindo-se como alternativa para os casais que já não sentem seus relacionamentos como satisfatórios (Krüger \& Werlang, 2005; Neumann \& Zordan, 2013). O término do casamento já vem sendo considerado por alguns autores como uma crise normativa do ciclo vital (Carter \& McGoldrick, 2008).

Quando a separação envolve filhos menores, a definição sobre a guarda dos mesmos é considerada como um momento importante para todo o sistema familiar, junto aos novos arranjos e reorganização da família. Conforme Silva (2012), a condução dessa etapa posterior ao divórcio e a forma como é vivenciada, poderão influenciar na relação e na adaptação de toda família. Alguns fatores são considerados relevantes nesse processo, entre os quais se destacam a guarda compartilhada e a relação coparental dos genitores (Brito \& Gonsalves, 2013).

\section{Guarda Compartilhada}

As modalidades de guarda presentes no nosso ordenamento jurídico são a guarda unilateral e a guarda compartilhada. No Brasil ainda adota-se, na maioria dos casos, o sistema de guarda unilateral. Em um grande número de casos a guarda é concedida à mãe, ficando o pai com o direito de visita (Quintas, 2010). Essa modalidade de arranjo pode provocar o afastamento entre pai e filhos, podendo levar a prejuízos em seu desenvolvimento (Brito, 2008). Atualmente, o instituto da guarda compartilhada passou a ser considerado por operadores do Direito e pesquisadores das ciências sociais como uma melhor alternativa, por privilegiar o melhor interesse da criança, conforme apontaram diferentes autores (Brito, 2005; Lamela, Figueiredo, \& Bastos, 2010; Quintas, 2010)

A Lei da Guarda Compartilhada (Lei $\mathrm{n}^{\circ}$ 11.698), instituída no Brasil em 2008 determina a responsabilização conjunta do pai e da 
mãe, além do deferimento dessa modalidade de guarda sempre que possível. A guarda compartilhada favorece o desenvolvimento das crianças e adolescentes, exatamente por possibilitar a continuidade da relação dos filhos com seus dois genitores (Akel, 2008), embora não implique em divisão equânime de tempo entre os genitores, e sim na divisão de responsabilidades do dever familiar entre a díade parental (Brito, 2008; Lago \& Bandeira, 2009).

A aplicação da guarda compartilhada tem sido considerada difícil, pois muitos operadores do Direito consideram necessária uma boa relação entre os genitores (Quintas, 2010), o que nem sempre acontece logo após a separação do casal. Além disso, fatores como a história prévia do casal, o relacionamento anterior entre o casal e os filhos, a faixa etária dos filhos, e a coparentalidade da díade parental, entre outros, são considerados como importantes para o bom funcionamento da guarda compartilhada (Lago \& Bandeira, 2009).

\section{Coparentalidade}

A coparentalidade pode ser definida como a relação entre dois adultos que partilham os cuidados e responsabilidades nos seus papéis parentais, com relação a uma ou mais crianças, em interações que correspondem às funções de proteção e educação dos filhos (Feinberg, 2003; Van Egeren \& Hawkins, 2004). Embora o subsistema conjugal e o subsistema coparental sejam inter-relacionados, são instâncias distintas. Dessa forma, a coparentalidade pode existir independente da conjugalidade, em um nível funcional, nas famílias divorciadas (Lavadera, Caravelli, \& Togliatti, 2012).

Nesse sentido, a coparentalidade tem sido considerada como um importante preditor do ajustamento de crianças e adolescentes, tanto em famílias nucleares, como em casos de separação da díade parental (Lamela, Figueiredo, et al., 2010; Teubert \& Pinquart, 2010). Diferentes autores têm proposto modelos de coparentalidade em que diversos componentes foram investigados, tais como, Maccoby, Depner e Mnookin (1990) que caracterizaram a coparen- talidade em três padrões: desengajado, cooperativo e conflitante; Margolin, Gordis e John (2001) que apontaram três dimensões: nível de conflito, cooperação e triangulação; e Feinberg (2003) que propôs quatro componentes: acordo ou desacordo nas práticas parentais, divisão do trabalho relacionado com a criança, suporte/sabotagem do papel coparental e gestão conjunta das relações familiares, entre outros. Observa-se que a coparentalidade não indica que haja necessariamente qualidade nas relações entre a díade parental (Van Egeren \& Hawkins, 2004), embora o envolvimento recíproco dos genitores sugira a presença de uma coparentalidade positiva (Lamela, Figueiredo, et al., 2010). A partir da literatura revisada, que aponta, conforme referido, a coparentalidade como um importante fator para que a guarda compartilhada seja bem sucedida, buscou-se investigar o fenômeno na prática, a partir da vivência de famílias que optaram por essa modalidade de guarda.

\section{Método}

\section{Participantes}

Participaram quatro famílias separadas, cujos filhos encontravam-se em situação de guarda compartilhada, sendo incluídos no estudo o pai e a mãe. As famílias foram selecionadas por conveniência, a partir de indicações e possuíam diferentes critérios entre si. As entrevistas foram realizadas individualmente, em locais escolhidos pelos participantes. Para preservar o sigilo, os participantes foram identificados com nomes fictícios e como F (família), de 1 a 4; P (pai) de 1 a 4; e M (mãe), de 1 a 4.

Família 1. À época da entrevista, João e Maria estavam separados de fato, há aproximadamente três meses, após uma união estável que durou oito anos. Ambos encontravam-se na faixa dos 40 anos e José, único filho do casal, estava com sete anos de idade. A família optou pela guarda compartilhada na prática, com alternância de residência, e intenções de formalização. Maria contava com apoio de uma babá e João com o apoio de sua família de origem. 
Família 2. Marco e Lara foram casados por seis anos e estavam separados há quase dois. Tiveram uma única filha, Bia, com seis anos de idade na ocasião da entrevista. Ambos encontravam-se na faixa dos trinta anos de idade. A guarda estabelecida foi compartilhada na prática, com alternância de residência, mudando logo depois para compartilhada. A filha ficou morando com a mãe. Ambos contavam com rede de apoio familiar. Lara já estava em novo casamento há um ano na ocasião da entrevista.

Família 3. Chico e Susi foram casados por sete anos e se separaram pouco depois de saber que ela estava grávida do único filho do casal. $\mathrm{Na}$ ocasião do estudo, Chico e Susi encontravam-se na faixa dos quarenta anos de idade e Ico estava com 12 anos. Ambos refizeram suas vidas em novos casamentos e contavam com rede de apoio. Eles optaram pela guarda compartilhada desde o início, sendo que o filho morava na casa da mãe.

Família 4. Lucas e Dani haviam se divorciado há seis anos, depois de quatorze anos de casados e duas filhas, Mia e Mila. Essas se encontravam com dezoito e vinte anos na ocasião da entrevista, Lucas na faixa dos cinquenta e Dani na faixa dos quarenta anos. Optaram pela guarda compartilhada, na prática e legalmente, sendo que as filhas ficaram morando com a mãe. Ambos contavam com rede de apoio familiar. Lucas havia se casado novamente, há cinco anos.

\section{Delineamento e Procedimentos}

O presente estudo teve caráter qualitativo/ exploratório, com delineamento de estudo de casos múltiplos cruzados (Yin, 2005). Foi realizado contato com um dos genitores de cada família indicada. Depois de feito o convite, o genitor contatado entrou em contato com o outro genitor a fim de consultar sobre sua participação. Uma vez confirmado o interesse agendavam-se os encontros individualmente nos locais escolhidos pelos participantes. As entrevistas variaram entre 60 e 120 minutos de duração.

O projeto foi aprovado pelo Comitê de Ética em Pesquisa do Instituto de Psicologia da Uni- versidade Federal do Rio Grande do Sul, sob o número 22803. Todos os participantes foram informados sobre os objetivos da pesquisa e assinaram o Termo de Consentimento Livre e Esclarecido.

\section{Instrumentos}

Ficha de Dados Sociodemográficos. Teve como finalidade recolher informações sobre as características dos participantes e dos filhos (e.g., idade, situação conjugal atual, tempo de separação, presença de rede de apoio).

Entrevista Guarda Compartilhada - Versão Díade Parental (Gadoni-Costa, Frizzo, \& Lopes, 2014). Foi baseada na literatura e no Modelo da Estrutura Interna e Contexto Ecológico da Coparentalidade de Feinberg (2003).

\section{Análise dos Dados}

Foi realizada análise qualitativa, baseada na compreensão dinâmica dos casos em uma perspectiva sistêmica, através da síntese de casos cruzados (Yin, 2005). A técnica de síntese de casos cruzados permite que seja feita a comparação de dados de casos individuais, segundo uma mesma estrutura, ou seja, estabelecer relações entre contextos diferentes, observando os aspectos em comum. As categorias foram inicialmente definidas com base no Modelo da Estrutura Interna e Contexto Ecológico da Coparentalidade de Feinberg (2003), bem como na literatura revisada resultando assim em duas categorias: guarda compartilhada e coparentalidade. A categoria guarda compartilhada teve como subcategorias: (a) decisão pela guarda compartilhada; (b) o cotidiano; (c) relacionamento, comunicação e a guarda compartilhada. A categoria coparentalidade teve como subcategorias: (a) acordo ou desacordo nas práticas parentais; (b) divisão do trabalho relacionado com a criança; (c) suporte/sabotagem do papel coparental; (d) gestão conjunta das relações familiares.

\section{Resultados e Discussão}

Os resultados serão apresentados e discutidos levando em consideração as dimensões de interesse deste trabalho, investigando como as 
famílias se mostraram na adaptação à guarda compartilhada na prática.

\section{Guarda Compartilhada}

Decisão pela Guarda Compartilhada. Para as famílias participantes deste estudo, a decisão pela guarda compartilhada ocorreu de forma diferente. Na Família 1, mesmo com incertezas, o pai se posicionou fortemente diante da possibilidade de só poder ver o filho de quinze em quinze dias. A partir de seu posicionamento, a discussão evoluiu para uma guarda compartilhada, com alternância de residência: “. . . Não me imagino vendo o José a cada quinze dias. Para mim é uma coisa que não me passa pela cabeça. Eu não quero deixar de estar presente na vida dele de forma alguma" (P1).

O momento de decisão pela modalidade de guarda dos filhos é permeado por dúvidas e sentimentos de insegurança. Segundo Brito (2005), quando se fala em compartilhamento da guarda, também são muitos os questionamentos sobre as consequências para os filhos e se poderá, ou não, dar certo. A guarda compartilhada busca o equilíbrio na divisão do tempo que cada genitor passa com os filhos, bem como a participação na educação dos mesmos.

Assim como P1, os pais ${ }^{2}$ separados, participantes de estudo realizado por Warpechowski e Mosmann (2012) também relataram que sentiam falta do convívio diário que tinham com seus filhos antes da separação, bem como o desejo de participar mais de suas vidas. Bottoli (2010) salientou, ao pesquisar a perspectiva do pai frente à paternidade e à separação conjugal, que é notório o surgimento de um "novo pai" em muitas famílias, no sentido de buscar uma paternidade mais ativa, mesmo que isso não seja feito da forma como gostariam. Entretanto, Martins (2009) salientou que, apesar das inúmeras e importantes mudanças no papel do pai, a presença de uma paternidade ausente ainda pode ser observada na literatura sobre o tema.

2 Neste estudo os termos pai/pais foram utilizados em referência ao sexo masculino. Para referência de pai+mãe foram utilizados os termos díade parental ou genitores.
Uma boa relação coparental após o divórcio pode amenizar a preocupação dos filhos em perder um dos genitores (Bottoli, 2010). Segundo Grisard (2010), é importante que os pais transmitam a ideia de que ambos continuarão a fazer parte da vida dos filhos, confirmando seus vínculos de afeto. A guarda compartilhada, ao colocar os pais em condições iguais de direito e deveres em relação ao filho, favorece que esta intimidade entre pais e filhos seja preservada, visto que a relação entre eles não é interrompida, o que pode levar à diminuição dos conflitos parentais, e atenuar as marcas negativas do divórcio.

Na Família 2, a decisão inicial foi pela guarda compartilhada, de comum acordo. Entretanto, no momento da formalização a operadora do Direito que conduziria o processo se posicionou de forma a confundir o ex-casal, pois sugeriu que a mãe solicitasse guarda unilateral, mesmo que na prática a guarda permanecesse compartilhada. A díade parental foi informada que não havia diferença entre as duas modalidades de guarda, conforme o relato de Marco (P2): "Ai foi quando a advogada dela . . começou a me dizer que a guarda unilateral era a mesma coisa que a guarda compartilhada, que eu tinha os mesmo direitos e que aquilo não mudava nada". Essa atitude por parte da advogada provocou novos conflitos entre eles, que já buscavam se adaptar aos novos arranjos, além de gerar insegurança.

Estudo realizado com operadores do Direito (Brito, 2005), apresentou achados em consonância com os do estudo em tela. Dúvidas e contrariedades quanto à guarda compartilhada foram mencionadas pelos entrevistados, embora alguns deles tenham concordado que as montagens jurídicas contribuem para que o pai, como visitante, participe de forma restrita na educação dos filhos. Tanto o relato de P2 como os achados do estudo mencionado acima indicam a necessidade de debates mais aprofundados, investigações e trocas de experiência, a fim de que o instituto da guarda compartilhada não fique restrito ao âmbito teórico.

$\mathrm{Na}$ Família 3, o nascimento do filho se deu após a separação do casal. Esse fato e a participação efetiva do pai nos primeiros cuidados com o bebê foram determinantes para que am- 
bos não tivessem dúvidas de que a guarda seria compartilhada entre eles. "Eu acompanhei todo o pré-natal dela, acompanhei o nascimento do Ico e, desde lá, nós nos conversamos quase que diariamente. ..." (P3).

O envolvimento do pai desde a gestação do filho, conforme relatado por Chico (P3), apesar de já separado de Susi, também foi abordado em estudo de Piccinini, Silva, Gonçalves, Lopes e Tudge (2004). Esses autores verificaram que o pai pode se envolver de forma expressiva, no âmbito emocional e comportamental, durante esse período. Embora a gestação seja considerada uma fase restrita ao universo feminino, Piccinini e colaboradores (2004) identificaram mudanças importantes quanto à experiência da paternidade nesse momento. Por outro lado, alguns pais participantes do referido estudo evidenciaram dificuldades na vinculação com o bebê, bem como na participação com os cuidados do mesmo (Piccinini et al., 2004). Essa variação no comportamento dos pais apontou que seu envolvimento, como aconteceu com P3, não pode ser generalizado. A experiência da família também indicou que compartilhar os cuidados de um filho, mesmo que não exista conjugalidade entre a díade parental, pode acontecer antes mesmo de seu nascimento.

A Família 4 não chegou a discutir a modalidade de guarda. Ela aconteceu de forma natural, como uma continuação do convívio existente entre os genitores e as filhas. Conforme Milano Silva (2006), a guarda compartilhada facilita que pais e mães continuem a agir como agiam na constância do casamento, ou seja, dividindo as responsabilidades e os cuidados com a prole e também compartilhando as decisões sobre suas vidas. A separação do casal não implica em término da família, e sim na transformação desse sistema, que se mantém como organização, apesar da díade parental não formar mais um casal (Cano, Gabarra, Moré, \& Crepaldi, 2009).

$O$ Cotidiano. A guarda dos filhos após a separação exige um esforço constante da díade parental no sentido de manter o bem estar dos filhos e perceber quando os arranjos estipulados não estão funcionando. Todo o sistema familiar deve ajustar-se à nova estrutura, e às novas cir- cunstâncias. A díade parental e os filhos precisam buscar compreender seus papéis nesta nova configuração (Deutsch, 2010), o que também está relacionado ao cotidiano na modalidade de guarda estabelecida. As famílias entrevistadas relataram vivências do cotidiano em guarda compartilhada, que indicaram a presença do desejo, de cada pai e cada mãe, em fazer dar certo. No caso da Família 1, a guarda compartilhada foi definida, entre eles, com alternância de residência, o que se mostrou complicado na prática, como pode ser observado na fala de P1:

. . numa segunda-feira que ele estava comigo e eu estava botando ele para dormir, dai ele comentou que ele estava triste. E eu perguntei "por que tu tá triste, filho?" e ele disse "por essa coisa de eu ter duas casas" ... (P1)

É importante observar que a separação do casal na Família 1, embora não sendo a primeira vez, havia sido recente, o que pode ter dificultado a adaptação do filho (Carter \& McGoldrick, 2008). O compartilhamento da guarda não implica em uma divisão igualitária de tempo entre a díade parental, nem em exigência de que a prole viva em duas casas (Brito, 2003). A confusão e o desconhecimento, tanto das famílias, como dos agentes jurídicos, sobre as peculiaridades do instituto da guarda compartilhada tem dificultado sua aplicação na prática.

A informalidade nas combinações apareceu como positiva na fala a seguir indicando mais uma vez que a presença do pai e da mãe no cotidiano contribuiu para a adaptação dos filhos ao novo momento de vida da família: "Não tinha nada formal. Elas foram morar comigo, e ele quando podia, ele pegava. . . . Sempre se colocou à disposição, mas não tinha, assim, hora determinada" (M4).

A separação conjugal não diminui o desejo do pai em exercer seu papel e continuar próximo de seus filhos. Entretanto, para que isso ocorra, é necessário que haja uma flexibilidade na relação com a prole, com a ex-mulher e até com ele próprio, no sentido de dar tempo para que as adaptações aconteçam. Como os padrões anteriores deixaram de existir, o pai precisa construir novas referências para o desempenho de seu pa- 
pel (Bottoli, 2010; Warpechowski \& Mosmann, 2012), como ocorreu com a Família 4.

A flexibilidade no remanejo das visitas e das combinações feitas anteriormente também foi observada nos relatos das famílias em guarda compartilhada. A vinheta a seguir ilustra uma situação em que o bem estar do filho e da díade parental foi priorizado:

. . chega em uma quarta-feira em que ele está com o pai e diz "ah, to com saudade da minha mãe". Nada impede que o João pegue e diga "eu te levo lá e tu dorme com ela"; ou o contrário também. (M1)

Em seu estudo sobre guarda compartilhada Dwyer (2010) destacou que as famílias não podem, nem devem manter o mesmo plano estabelecido inicialmente, após a separação, ao longo do tempo. Ao passar dos meses e anos, as necessidades de desenvolvimento das crianças mudam, e o plano de parentalidade deve mudar em conformidade com essas necessidades. As circunstâncias da díade parental também podem mudar ao longo do tempo, como por exemplo, como um novo casamento de um dos genitores.

Relacionamento, Comunicação e a Guarda Compartilhada. A boa relação entre a díade parental tem sido considerada como determinante para a definição da guarda compartilhada por parte dos magistrados, aparecendo como o principal argumento na dificuldade de aplicação do referido instituto (Brito \& Gonsalves, 2013; Quintas, 2010). As famílias participantes deste estudo relataram níveis diferentes de relacionamento e de comunicação após a separação. As famílias 1 e 4 referiram dificuldades de comunicação, como pode ser conferido no depoimento de P4:

O diálogo já era dificil entre nós antes do casamento e depois se tornou mais difícil ainda. . . Mas mesmo com essa dificuldade acho que foi viável ter a guarda compartilhada, uma coisa não tem a ver com outra. (P4)

A Família 2 passou por mudanças no relacionamento e no nível de comunicação após a separação. Embora tenham diminuído o contato após o novo casamento de M2, os conflitos também foram reduzidos: "Em um primeiro momento não era muito bom, mas agora . . a situação se acomodou um pouco, se ajeitou, enfim. Passamos por um periodo de adaptação para poder chegar a um nivel de comunicação mais aprimorado" (M2).

Em estudo realizado sobre coparentalidade, Augustin e Frizzo (no prelo) apontaram que o acordo e o diálogo dos pais em relação aos filhos e a confiança depositada no outro genitor foi determinante para que uma das famílias conseguisse resolver suas divergências. Para essas mesmas autoras, a comunicação e a confiança entre o casal serviram como facilitador nos acordos e como forma de auxiliar na resolução de conflitos. A pesquisa de Markham e Coleman (2012) sobre mães divorciadas e sua experiência coparental, identificou que as mães com relações de coparentalidade cooperativa, ao contrário das que mantinham relações conflituosas, mostraram-se com mais condições de se comunicar diretamente com os ex-parceiros sobre seus filhos, além de lidar melhor com as diferenças nos estilos parentais. As mesmas autoras destacaram que provavelmente essas díades parentais já tivessem um bom relacionamento coparental antes mesmo de adotar a guarda compartilhada.

\section{Coparentalidade}

Conforme já referido, a coparentalidade neste estudo foi investigada a partir do Modelo da Estrutura Interna e Contexto Ecológico da Coparentalidade de Feinberg (2003), na qual foram propostos quatro componentes que se sobrepõem, conforme as subcategorias a seguir.

Acordo ou Desacordo nas Práticas Parentais. No modelo de Feinberg (2003), esse primeiro componente da coparentalidade representa o grau de acordo ou desacordo da díade parental sobre uma série de temas relacionados com filhos, entre os quais: valores morais, expectativas de comportamento e disciplina, necessidades emocionais dos filhos e segurança, entre outros.

Conforme o relato de $\mathrm{P} 4$, as necessidades emocionais das filhas não eram atendidas pela mãe da forma como ele considerava adequado, o que se configurou como desacordo:

Existe desacordo na minha parte com relação à forma como ela lida ou negocia as coisas com as filhas. Elas já cresceram e ela 
continua adotando uma postura típica... . de pai ou mãe de criança pequena aonde as coisas são impostas. Eu acho que isso está inadequado. (P4)

Diversos autores (Lamela, Castro, \& Figueiredo, 2010; Maccoby et al., 1990) afirmaram que muitos pais têm dificuldades em separar a conjugalidade vivida com sua ex-mulher da coparentalidade que permanece depois da separação, principalmente $\operatorname{logo}$ após a ocorrência desse evento. Tal situação, segundo Lamela, Castro, et al. (2010), poderia facilitar o desenvolvimento de uma coparentalidade paralela, na qual pai e mãe, embora compartilhando os cuidados com a prole, realizariam essas tarefas de forma descoordenada pela falta de comunicação adequada.

Na Família 3 também foram constatados desacordos entre a díade parental:

Nunca existiu acordo . . . eu sempre ouvi assim: que havia maneira dele [o filho] fazer as coisas aqui e maneira de ele fazer as coisas lá na casa dela. . . Essa foi uma briga constante... (P3)

Para Feinberg (2003), o desacordo nas práticas parentais, por si só, não produz resultados negativos na família. Algumas díades parentais são capazes de "concordar em discordar [tradução da autora]" (p. 102) de forma equilibrada e, assim, manter o apoio coparental e a negociação das diferenças (Feinberg, 2003; Grych \& Fincham, 1993).

Divisão do Trabalho Relacionado com a Criança. O segundo componente de coparentalidade segundo o modelo de Feinberg (2003), se relaciona com a divisão do trabalho e das responsabilidades referentes às rotinas diárias envolvidas na educação dos filhos, além das tarefas domésticas e outras responsabilidades relacionadas com a prole.

A maioria dos estudos nessa área teve foco em famílias intactas, nas quais as mães relataram que a questão do trabalho doméstico é o principal motivo de conflito no período puerperal (Cowan \& Cowan, 1988; Feinberg, 2003). Para diversos autores, o ponto de vista da mãe é fundamental, já que essas assumem sozinhas, na maioria das vezes, as responsabilidades para muitas questões relacionadas com os filhos pequenos. Esses achados contrariam o depoimento de Chico (P3), que assumiu para si tarefas, como dar banho no filho desde pequeno, momentos considerados por ele como importantes para a relação pai/filho. Observa-se que na Família 3, o casal já havia se separado: “. . . quando eu dei o primeiro banho, meio que ficou como meu encargo no primeiro mês. Então eu ia lá, dava banho nele todos os dias" (P3).

$\mathrm{O}$ envolvimento do pai com as tarefas e cuidados com o bebê, logo após seu nascimento, foi determinante para que a guarda se constituísse como compartilhada. O exemplo do presente estudo sugeriu que, independente da configuração familiar ou da existência de conjugalidade, quando há desejo por parte da díade parental, é possível que o pai assuma seu lugar na vida do filho desde os primeiros momentos.

De um modo geral, o equilíbrio entre regras estruturadas e flexibilidade, pode ser o ideal para o funcionamento familiar (Feinberg, 2003). No entanto, em situações estressantes, como por exemplo, o ingresso de um filho na escola, ou no caso das famílias entrevistadas, a situação de separação, uma maior flexibilidade pode favorecer que as necessidades sejam atendidas, o que em uma situação com regras mais estruturadas talvez não fosse possível. Além disso, na medida em que novos desafios e dificuldades vão sendo vivenciados, arranjos rígidos podem atrapalhar na busca de soluções. Na Família 3 algumas regras flexíveis se tornaram mais estruturadas com o passar do tempo, a fim de contemplar as novas necessidades e demandas, após o novo casamento de um dos genitores:

... A minha atual mulher mais ou menos cobra . . que tenha as coisas assim mais organizadas. . . o que eu acho muito bom da guarda compartilhada é que ela permite isso. Qualquer momento as pessoas podem chegar e dizer "olha, vamos facilitar a nossa vida?" (P3)

Suporte/Sabotagem do Papel Coparental. Esse componente da coparentalidade, segundo o modelo proposto por Feinberg (2003), relaciona-se ao apoio mútuo entre a díade parental, no 
sentido de reconhecer a competência do outro como pai/mãe, além de sustentar as decisões e a autoridade parental do outro genitor.

O grau de suporte, em oposição à sabotagem, tem sido associado ao ajustamento entre pais e filhos (Feinberg, 2003). Alguns autores salientaram que casais que se apoiam mutuamente e são capazes de discutir as divergências são mais propensos a ter uma coparentalidade positiva do que aqueles que não o fazem (Cabrera, Shannon, \& La Taillade, 2009), como foi observado na colocação da Família 4: "Olha, sempre conseguimos administrar muito bem esse aspecto de não ficar desdizendo um ao outro, colocando conflitos e tal. Isso foi muito bem administrado apesar da extrema dificil comunicação" (P4).

Também nesse sentido, estudos com famílias americanas de classe média constataram que os pais eram mais presentes nas vidas dos filhos em idade pré-escolar quando percebiam que as mães tinham confiança neles como pais. Estes achados são consistentes com uma visão sistêmica da família, que sugere que o subsistema parental do pai está mais ligado à parentalidade do que o subsistema parental da mãe (Cabrera et al., 2009; McBride \& Rane, 2001). Em consonância com esses achados, o estudo de Pedro (2013) realizado em Portugal, sobre variáveis mediadoras e moderadoras na relação conjugal e entre pais e filhos, apontou que a paternidade se encontra mais fortemente associada aos contributos do cônjuge para a cooperação interparental, do que a maternidade.

Gestão Conjunta das Relações Familiares. O quarto componente do modelo de Feinberg (2003) pressupõe que a administração das interações familiares é da competência do subsistema parental, levando em conta três direções: conflito, coalizão e equilíbrio. No conflito, a exposição dos filhos a situações de hostilidade pode prejudicar a coparentalidade no sentido da responsabilidade conjunta da díade em proporcionar segurança física ou emocional à prole. Embora as famílias deste estudo tenham relatado situações em que os filhos foram expostos ao conflito, os episódios ocorreram principalmente durante o casamento e na fase pré-separação. Nas fases subsequentes, já com o compartilha- mento da guarda, o esforço para evitar essas situações se mostrou positivo. A díade parental da Família 1 denotou competência para lidar com tais situações, fortalecendo seu papel protetivo junto ao filho, que percebeu os pais a seu lado, como uma "equipe":

. . e estamos nós dois juntos em função dele . . . ele passou para a psicóloga, inclusive, foi que "ah, eles fizeram isso e agora eles estão trabalhando em equipe", ou seja, antes a gente estava trabalhando cada um para um lado e agora a gente está trabalhando em um foco que era ele. (M1)

$\mathrm{Na}$ coalizão, a díade parental expõe os filhos ao conflito, levando-os a tomar partido ou a ficar envolvidos na busca de solução pelos desentendimentos dos pais. Essa busca pelo filho pode ser ostensiva ou dissimulada. A coalizão acontece quando as fronteiras não são nítidas, podendo levar os filhos a agir como aliados de um ou outro genitor (Feinberg, 2003; Minuchin 1985), conforme ilustrado na vinheta:

E aí, além disso, nos últimos tempos . . . ele percebeu que havia um desarranjo e começou a jogar com isso. E ela ao invés de participar e contribuir, já chegava me acusando de ser agressivo, de gritar com ele, de ser estúpido, na frente dele. ( $\mathrm{P} 1)$

Nas demais famílias entrevistadas não houve relato de situações expressas de triangulação. $\mathrm{O}$ trecho a seguir ilustra o esforço de M2 para evitar situações de coalizão e conflito: "Eu acho que eu faço muito mais para não gerar estresse do que ele. Então, de vez em quando eu abro muito mais a mão, e dou mais opções justamente para não gerar um estresse entre eu e ele" (M2).

Quanto ao equilíbrio, conforme Feinberg (2003), o foco recai na interação pais/filhos, considerando a proporção relativa de tempo que cada genitor se envolve com a prole quando o outro genitor também está presente. As famílias deste estudo relataram poucas situações em que se encontravam na presença um do outro, com o filho. Entretanto, a gestão conjunta apareceu de outras formas:

. . . a gente deixou bem claro com o José: eu vou continuar sendo tua mãe, ele vai continuar sendo o teu pai e tudo o que a 
gente precisar fazer junto para ti, a gente vai fazer. . . e eu geralmente quando tenho uma dúvida, eu ligo para o João. (M1)

Neumann e Zordan (2013) apontaram, a partir de seu estudo sobre relacionamento entre irmãos após a separação dos pais, que quando a díade parental resolve seus conflitos conjugais na separação e cumprem suas tarefas adequadamente, o sistema familiar tende a se organizar de forma mais eficaz. Os achados do referido estudo também indicaram que a manutenção da coparentalidade permitiu aos filhos permanecer em seu papel no sistema familiar, vivenciando as diferentes fases do pós-divórcio de forma menos problemática.

\section{Considerações Finais}

O presente artigo apresentou um estudo realizado com quatro famílias que optaram pela modalidade de guarda compartilhada dos filhos após a separação conjugal, selecionados por conveniência. A guarda compartilhada, sua aplicação prática, bem como a coparentalidade das díades parentais entrevistadas foram investigadas a partir da vivência dessas famílias. O estudo foi norteado pela literatura revisada sobre o tema, bem como pelo Modelo da Estrutura Interna e Contexto Ecológico da Coparentalidade de Feinberg (2003).

Em consonância com a literatura que investiga o papel do pai após o divórcio (Lamb, 2004; Lamela, Castro, et al., 2010) e a coparentalidade (Brito, 2008; Feinberg, 2003), a aplicação da guarda compartilhada foi considerada positiva tanto pelos pais, como pelas mães entrevistados neste estudo, embora tenham sido constatadas dificuldades, o que também acontece em outras modalidades de guarda. Tanto as mães, quanto os pais entrevistados, revelaram manter o envolvimento com seus filhos e participar de suas vidas, apesar da nova configuração familiar. A coparentalidade entre as díades parentais se revelou positiva na maior parte do tempo, o que certamente contribuiu para que os novos arranjos fossem bem sucedidos e as dificuldades superadas.

Quanto à participação do pai, foi possível perceber que esses já eram pais envolvidos e apropriados de seu papel parental antes mesmo da separação. A própria participação no estudo e o desejo de contribuir através de seus depoimentos são indicativos dessa constatação.

O uso de uma amostra heterogênea contribuiu para demonstrar como o compartilhamento da guarda se deu na prática em diferentes situações, como faixa etária da díade parental, número e idade dos filhos, presença ou não de novos cônjuges, entre outras. Nesse sentido, foi possível observar que a separação conjugal e um novo casamento não são necessariamente, vivências com aspectos só negativos. Também podem ser consideradas como oportunidades de crescimento e desenvolvimento de novas habilidades de comunicação e resolução de problemas entre todo o sistema familiar (Leme, Del Prette, \& Coimbra, 2013; Mota \& Matos, 2011).

Como limitações deste estudo, destaca-se o número reduzido de participantes, bem a como a não participação de outros integrantes do sistema familiar, como os filhos. Novos estudos podem atentar para a inclusão dos filhos a fim de abarcar a complexidade de visões dos fenômenos pelos diferentes subsistemas familiares. Sugerem-se novas pesquisas com amostras mais abrangentes e diferentes abordagens metodológicas, como por exemplo, estudos longitudinais em diferentes momentos da aplicação da guarda compartilhada. Entretanto, espera-se que as considerações deste estudo possam contribuir para o tema relacionado à aplicação da guarda compartilhada e a relação coparental nessas famílias.

\section{Referências}

Akel, A. C. S. (2008). Guarda compartilhada: Um avanço para a família. São Paulo, SP: Atlas.

Augustin, D., \& Frizzo, G. (no prelo). A coparentalidade ao longo do desenvolvimento dos filhos: Estabilidade e mudança no $1^{\circ}$ e $6^{\circ}$ ano de vida. Interação em Psicologia.

Bottoli, C. (2010). Paternidade e separação conjugal: A perspectiva do pai (Dissertação de mestrado, Programa de Pós-Graduação em Psicologia, Universidade Federal de Santa Maria, RS, Brasil). 
Brito, L. M. T. (2003). Igualdade e divisão de responsabilidades: Pressupostos e consequências da guarda conjunta. In G. C. Groeninga \& R. C. Pereira (Eds.), Direito de família e psicanálise: Rumo a uma nova epistemologia (pp. 325-337). Rio de Janeiro, RJ: Imago.

Brito, L. M. T. (2005). Guarda compartilhada: Um passaporte para a convivência familiar. In Associação de Pais e Mães Separados (Ed.), Guarda compartilhada: Aspectos psicológicos e jurídicos (pp. 53-72). Porto Alegre, RS: Equilíbrio.

Brito, L. M. T. (2008). Família e separações: Perspectivas da Psicologia Jurídica. Rio de Janeiro, RJ: Editora da Universidade do Estado do Rio de Janeiro.

Brito, L. M. T., \& Gonsalves, E. N. (2013). Guarda compartilhada: Alguns argumentos e conteúdos da jurisprudência. Revista Direito GV, 9(1), 299 318. doi:10.1590/S1808-24322013000100011

Cabrera, N. J., Shannon, J. D., \& La Taillade, J. J. (2009). Predictors of co-parenting in Mexican American families and direct effects on parenting and child social emotional development. Infant Mental Health Journal, 30(5), 523-548. doi:10.1002/imhj.20227

Cano, D. S., Gabarra, L. M., Moré, C. O., \& Crepaldi, M. A. (2009). As transições familiares do divórcio ao recasamento no contexto brasileiro. Psicologia: Reflexão e Crítica, 22(2), 214-222. doi:10.1590/S0102-79722009000200007

Carter, B., \& McGoldrick, M. (2008). As mudanças no ciclo de vida familiar: Uma estrutura para a terapia familiar. Porto Alegre, RS: Artmed.

Cowan, C. P., \& Cowan, P. A. (1988). Who does what when partners become parents: Implications for men, women, and marriage. Marriage \& $\mathrm{Fa}$ mily Review, 12(3-4), 105-131. doi:10.1300/ J002v12n03_07

Deutsch, R. M. (2010). When the conflict continues: The right parenting plan can help defuse tensions. Family Advocate, 33(1), 40-45.

Dwyer, S. A. (2010). How to share parenting: So that 'equal access' means 'the best of both parents'. Family Advocate, 33(1), 4-7.

Feinberg, M. E. (2003). The internal structure and ecological context of coparenting: A framework for research and intervention. Parenting, Science and Practice, 3(2), 95-131. doi:10.1207/ S15327922PAR0302_01
Gadoni-Costa, L. M., Frizzo, G. B., \& Lopes, R. C. S. (2014). Entrevista Guarda Compartilhada versão díade parental. In L. M. Gadoni-Costa, A guarda compartilhada sob a ótica dos operadores do Direito e da díade parental: Um estudo exploratório (Tese de doutorado, Programa de Pós-Graduação em Psicologia, Universidade Federal do Rio Grande do Sul, Porto Alegre, RS, Brasil).

Grisard, W., Filho. (2010). Guarda compartilhada: Um novo modelo de responsabilidade parental. São Paulo, SP: Editora Revista dos Tribunais.

Grych, J. H., \& Fincham, F. D. (1993). Children's appraisals of marital conflict: Initial investigations of the cognitive-contextual framework. Child Development, 64(1), 215-230. doi:10.1111/j.1467-8624.1993.tb02905.x

Krüger, L. L., \& Werlang, B. S. G. (2005). Estudo da ruptura do vínculo conjugal através da avaliação do casamento. Pensando Famílias, 7(9), 65-79.

Lago, V. M., \& Bandeira, D. (2009). A Psicologia e as demandas atuais do Direito de Família. Psicologia, Ciência e Profissão, 29(2), 290-305.

Lamb, M. E. (2004). The changing roles of fathers. In J. Shapiro \& L. Diamond (Eds.), Becoming a father: Contemporary, social, developmental, and clinical perspectives (pp. 18-35). New York: Springer.

Lamela, D., Castro, M., \& Figueiredo, B. (2010). Pais por inteiro: Avaliação preliminar da eficácia de uma intervenção em grupo para pais divorciados. Psicologia: Reflexão e Crítica, 23(2), 334344. doi:10.1590/S0102-79722010000200016

Lamela, D., Figueiredo, B., \& Bastos, A. (2010). Adaptação ao divórcio e relações coparentais: Contributos da teoria da vinculação. Psicologia: Reflexão e Crítica, 23(3), 562-574. doi:10.1590/S0102-79722010000300017

Lavadera, A. L., Caravelli, L., \& Togliatti, M. M. (2012). Child custody in Italian management of divorce. Journal of Family Issues, 34, 1536. doi:10.1177/0192513X12462528

Leme, V. B. R., Del Prette, Z. A. P., \& Coimbra, S. (2013). Práticas educativas parentais e habilidades sociais de adolescentes de diferentes configurações familiares. Psico (Porto Alegre), 44(4), 560-570.

Maccoby, E., Depner, C., \& Mnookin, R. (1990). Coparenting in the second year after divor- 
ce. Journal of Marriage \& the Family, 52, 141155. doi: $10.2307 / 352846$

Margolin, G., Gordis, E. B., \& John, R. S. (2001). Coparenting: A link between marital conflict and parenting in two-parent families. Journal of $\mathrm{Fa}$ mily Psychology, 15(1), 3-21. doi:10.1037/08933200.15.1.3

Markham, M. S., \& Coleman, M. (2012). The good, the bad, and the ugly: Divorced mothers' experiences with coparenting. Family Relations, 61, 586-600. doi:10.1111/j.17413729.2012.00718.x

Martins, A. C. (2009). Paternidade: Repercussões e desafios para a área de saúde. Revista Pós Ciências Sociais, 1(11). Recuperado em http://www. ppgcsoc.ufma.br/index.php?option=com_con tent $\&$ view $=$ article $\&$ id $=307 \&$ catid $=72 \&$ Item $\mathrm{id}=114$

McBride, B. A., \& Rane, T. R. (2001). Father/male involvement in prekindergarten at-risk programs: An exploratory study. Early Childhood Research Quarterly, 16, 77-93.

Milano Silva, A. M. (2006). Guarda compartilhada. São Paulo, SP: Editora de Direito.

Minuchin, P. (1985). Families and individual development: Provocations from the field of family therapy. Child Development, 56(2), 289-302. doi:10.2307/1129720

Mota, C. P., \& Matos, P. M. (2011). Adolescência e conflitos parentais: Uma perspectiva de resiliência. In P. M. Matos, C. Duarte, \& M. E. Costa (Eds.), Famílias: Questões de desenvolvimento e intervenção (pp. 125-150). Porto, Portugal: LivPsic.

Neumann, A. P., \& Zordan, E. P. (2013). As reverberações da separação conjugal dos pais no relacionamento entre irmãos. Pensando Famílias, 17(2), 35-47.
Pedro, M. F. (2013). Relação conjugal e relação pais-filhos: Estudo de variáveis mediadoras $e$ moderadoras (Tese de doutorado, Faculdade de Psicologia, Universidade de Lisboa, Portugal).

Piccinini, C. A., Silva, M. R., Gonçalves, T. R., Lopes, R. S., \& Tudge, J. (2004). O envolvimento paterno durante a gestação. Psicologia: Reflexão e Crítica, 17(3), 303-314. doi:10.1590/S010279722004000300003

Quintas, M. R. A. (2010). Guarda compartilhada: De acordo com a Lei $n^{\circ} 11.698 / 08$. Rio de Janeiro, RJ: Forense.

Silva, L. S. N. (2012). Boas práticas dos programas psicoeducacionais para pais separados/divorciados (Dissertação de mestrado, Faculdade de Psicologia, Universidade de Lisboa, Portugal).

Teubert, D., \& Pinquart, M. (2010). The association between coparenting and child adjustment: A meta-analysis. Parenting, 10(4), 286-307. doi:1 $0.1080 / 15295192.2010 .492040$

Van Egeren, L., \& Hawkins, D. (2004). Coming to terms with coparenting: Implications of definition and measurement. Journal of Adult Development, 11(3), 165-178. doi:10.1023/ B:JADE.0000035625.74672.0b

Warpechowski, A., \& Mosmann, C. (2012). A experiência da paternidade frente à separação conjugal: Sentimentos e percepções. Temas em Psicologia, 20(1), 247-260.

Yin, R. K. (2005). Estudos de caso: Planejamento e métodos. Porto Alegre, RS: Bookman.

Recebido: $28 / 07 / 2014$

$1^{a}$ revisão: $24 / 10 / 2014$ Aceite final: 27/10/2014 